(c) American Dairy Science Association, 2004.

\title{
A Review of International Standards and the Scientific Literature on Farm Milk Bulk-Tank Sampling Protocols
}

\author{
L. Goodridge, ${ }^{1}$ A. R. Hill, ${ }^{2}$ and R. W. Lencki ${ }^{2}$ \\ ${ }^{1}$ Department of Animal Science, University of Wyoming, \\ Laramie 82071 \\ ${ }^{2}$ Department of Food Science, University of Guelph, \\ Ontario, Canada N1G 2W1
}

\begin{abstract}
Adequate agitation is required to ensure homogeneity before sampling from on-farm bulk tanks, but excessive agitation may cause churning with a resulting loss of milk quality. Homogeneity can be assured by thorough mixing before a sample is taken and can also be combined with intermittent agitation of the bulk tank. There is general but qualified agreement among various countries and agencies, such as the IDF, that $5 \mathrm{~min}$ of agitation for small, and $10 \mathrm{~min}$ for large, quiescent farm-milk bulk tanks is required to ensure sample homogeneity. However, no empirical studies are cited to support these standards. The few studies that examined bulk-tank mixing estimate required agitation times of 8 to $10 \mathrm{~min}$ or longer, depending on the size of the tank. If intermittent agitation is practiced, mixing for 1 to 2 min before sampling is considered acceptable in some jurisdictions but, once again, empirical supporting evidence is absent. Automatic samplers decrease the amount of time needed to obtain a sample from the bulk tank, but both intermittent agitation and agitation during milk transfer are still recommended to minimize fat residue accumulation in the bulk tank. Systematic studies are needed to establish mixing protocols that assure accurate sampling for all tanks in a given jurisdiction.
\end{abstract}

(Key words: bulk tank agitation, sampling, standards)

Abbreviation key: DFO = Dairy Farmers of Ontario, DPC = Dairy Practices Council, IDF = International Dairy Federation, IAFP = International Association of Food Protection.

\section{INTRODUCTION}

Improperly agitated milk is a major source of estimate variability of both composition and bacteria

Received November 28, 2003.

Accepted April 18, 2004.

Corresponding author: A. R. Hill; e-mail: arhill@uoguelph.ca. counts of farm bulk-milk samples (Marshall and Shelley, 1981). Variation is mainly due to gravity creaming and the association of bacteria with fat globules, which causes both fat and bacteria to concentrate on the surface (Belknap et al., 1978; Jackson, 1981). There is also evidence that somatic cells also accumulate at the surface of poorly mixed milk (Belknap et al., 1978).

Our particular interest in farm bulk-tank agitation began with a request from the Dairy Farmers of Ontario (DFO) to examine the efficiency of their current bulkmilk tank agitation and sampling protocol. Ontario has had a long-standing requirement that milk be agitated for $5 \mathrm{~min}$ before a sample is taken. More recently, there has also been a requirement that bulk tanks undergo intermittent mixing for 5 min every hour. However, a study was never undertaken to determine if agitation time before sampling could be reduced if intermittent mixing was implemented. Whereas it is evident that any protocol must ensure that the milk inside the bulk tank is homogeneous so that a representative sample can be obtained, excessive mixing could lead to the deterioration of milk quality due to the disruption of milkfat globules. Another incentive for reexamining the current protocol was economic: the $\mathrm{DFO}$, which represents 6000 dairy farmers (DFO, 2002), estimates that reducing agitation time from 5 to 2 min would save about US $\$ 1.2$ million per year in Ontario due to more efficient use of both trucks and truck drivers (D. Nolan, Transportation Manager, DFO, personal communication, 2002).

The purpose of this study was to 1) summarize the current world standards on bulk-tank sampling to see whether there is any consensus on this issue, and 2) examine the literature on bulk milk tank mixing to determine whether there is currently any scientific basis for choosing an optimum sampling protocol. The results obtained will help determine whether further study is required before implementing changes in the current sampling protocol.

\section{CURRENT INTERNATIONAL STANDARDS}

The Ontario Milk Act (OMAF, 1983) states that bulktank milk must be agitated for at least 5 min prior to 
sampling. Other Canadian provinces also use the $5 \mathrm{~min}$ standard (c.f., FPLQ, 1999; MMP, 1999), although it is not officially legislated by all Canadian provinces.

In the United States, 2 guidelines appear to be common reference points with respect to milk agitation. First, the states of Connecticut, Delaware, Kentucky, Maine, Maryland, Massachusetts, New Hampshire, New Jersey, New York, Ohio, Pennsylvania, Rhode Island, Vermont, Virginia, Wisconsin, West Virginia, and probably others, follow the Dairy Practices Council (DPC) guideline entitled "Farm Bulk Tank Collection Procedures," which states the following (DPC, 1991; State of Wisconsin, 1999):

"The milk should be adequately agitated prior to sampling. Generally speaking, adequate agitation times are five minutes for tanks under 1,000 gallons $(3,800 \mathrm{~L})$ and 10 min for tanks [of] 1,000 gallons or more. Additional agitation time may be required under certain conditions."

The DPC includes representatives from several national bodies, including the State Departments of Health \& Agriculture, the Federal Departments of Health \& Agriculture, and various state and national industry and academic organizations. Second, New York State (and probably other states, although we have no specific knowledge to that effect) follows "Standard Methods for the Examination of Dairy Products" (APHA, 1992), which prescribes the following:

"Agitate milk in a farm holding cooling tank for at least 5 min immediately before sampling. Agitate contents of farm storage tanks of more than $5,700 \mathrm{~L}(1,500$ gal) for $10 \mathrm{~min}$, or as required by the manufacturer."

The "as required by the manufacturer" statement is of limited value. After contacting the 4 tank manufacturers that produce approximately $90 \%$ of all the bulk milk tanks in Ontario (DeLaval, Peterborough, ON; Mueller, Springfield, MO; Westfalia Surge, Naperville, IL; Bou-matic Dari-kool, Madison, WI), we found that they did not recommend any specific agitation times for their tanks.

The New Zealand Farm Dairy Code of Practice makes the apparently unique prescription that all bulk tanks should be continuously agitated (R. Andela, Fonterra Co-operative Group Ltd., personal communication, 2003). It also specifies the following agitation conditions for storage silos and vats:

"Silos and vats shall be provided with continuous agitation sufficient to thoroughly mix the milk to give a variation in fat content of less than $0.1 \%$ in milk volumes down to $10 \%$ of the rated capacity of the vat or silo, prevent thermal layering (the variation in temperature in the vat or silo shall not exceed $1^{\circ} \mathrm{C}$ ), [and] ensure that foaming or "churning" of milk does not occur."
R. Andela, Milk Quality Manager, Fonterra Co-operative Group Ltd. (personal communication, 2003), advised that recent tests demonstrate that, with continuous agitation, these conditions are being met for silos up to $30,000 \mathrm{~L}$.

For Australia, R. Greenall, Director, National Milk Harvesting Center, Ellinbank, Victoria (personal communication, 2003), advised that there is no national Australian standard for bulk-milk agitation prior to sampling, and that safety codes, such as the Code of Practice for Dairy Food Safety in the state of Victoria (DFSV, 2003), prescribe only the milk collection temperature, namely, a maximum of $5^{\circ} \mathrm{C}$. Greenall (personal communication, 2003) further suggested that any existing agitation standards are prescribed by dairy factories and are "loosely based on IDF protocol."

The International Dairy Federation (IDF) protocol, as defined in IDF Standard 50B (IDF, 1985), states:

"Mechanically agitate the milk for at least $5 \mathrm{~min}$ until sufficient homogeneity is obtained. If the tank is equipped with a periodical, time-programmed agitation system, sampling may be carried out after a short duration of agitation ( 1 to $2 \mathrm{~min}$ )."

Although there is no apparent empirical support for this protocol, C. Brookes, IDF Methods Standards Steering Group Assistant, Brussels (personal communication, 2003), advised that: 1) the same agitation protocol was prescribed in the 1995 edition of Standard 50C (IDF 1995); 2) IDF Standard 50C is equivalent to EN ISO 707:1997; 3) during the years since 1985, no IDF or ISO expert members commented on milk agitation standards; and 4) all EU countries are obliged to follow the EU standards. Note also that the IDF standard stated above does not specify frequency or duration of intermittent agitation.

In the United Kingdom, according to the Milk Marque Drivers Handbook (Anonymous, 1997), expected agitation is 2 min along with timed interval agitation, a protocol similar to that suggested in IDF Standard 50C (IDF, 1995). However, once again, the frequency or duration of intermittent agitation is not specified.

In summary, there is general, but not unequivocal, agreement among various jurisdictions and agencies that milk agitation for 5 and $10 \mathrm{~min}$ is required for small and large quiescent bulk tanks, respectively. When intermittent agitation is practiced, anywhere from 1 to 5 min of mixing is considered acceptable. New Zealand, which requires continuous agitation, is the exception. However, with the exception of New Zealand, there does not appear to be any specific studies to support a particular standard and rarely are precise parameters for intermittent agitation specified. 


\section{MIXING TIME STUDIES}

\section{Small-Scale Milk Mixing}

It has long been recognized that fat globules rise to the surface of fresh milk as cream; therefore, it must be ensured that the body of milk to be tested is homogeneous just prior to sample collection (Van Slyke, 1927). On a small scale, mixing is a relatively simple operation. Uniform composition of milk collected in pails can be achieved by pouring the milk from one pail to another. Alternatively, the milk is mixed with a dipper (Goss, 1953). For milk stored in single cans, the milk can be stirred with an up and down, circular motion of a disk-shaped stirring rod; the disc should be placed on the bottom of the can, pulled up on the near side of the can, and then pushed down on the far side (Davis, 1951; Goss, 1953). It has been suggested that this complete circular motion should be repeated at least 10 times to ensure that cream adhering to the shoulder of the can is mixed well with the thinner milk in the lower part of the can. Alternatively, the milk can be mixed by pouring the entire contents into an empty vessel and back again 3 times (i.e., 6 transfers). Following thorough mixing, a portion of the milk is immediately removed and transferred to a clean, dry sample bottle. These methods are still relevant wherever small storage vessels are in use, such as in countries where the cow milk industry is not modernized or where milk volumes are low (e.g., storage of sheep and goat milk).

\section{Farm Bulk-Tank Mixing}

Adequate mixing before sampling is perhaps even more critical with modern large-scale farm bulk tanks. Unfortunately, as Jackson (1981) has previously discussed, the published data on the agitation of storage tanks and tankers is relatively sparse and rather vague. Jackson (1981) does give a detailed description of manual, mechanical, and air agitation systems for tankers and bulk tanks, and provides a few examples of milkfat settling and mixing curves. However, the data published in this work are limited and would not be sufficient to provide quantitative guidance regarding appropriate mixing times.

The earliest references we could find to what has become the commonly prescribed 5-min standard were in Davis (1951) and Goss (1953), who both advised that milk in farm bulk tanks must be thoroughly mixed with a sufficiently large plunger or by allowing a motordriven agitator or air compressor to run for several (usually 5) minutes. However, the placement of "usually 5 " in parentheses is likely indicative of the uncertainty about how long a bulk tank should be agitated.
Goss (1953) advised that agitation time should be determined using a series of milkfat samples taken from a full tank at specified time intervals (e.g., 3 or 4 min) while mixing is in progress, until at least 5 milkfat tests stabilize at a definite value. Samples are obtained from the top and bottom, and from near and extreme distances from the source of agitation. If the design of the tank makes it impossible to remove samples with the agitator in operation, then samples are drawn through the outlet valve (Goss, 1953). This raises the question of how to define "definite value." The International Association of Food Protection (IAFP, 1994) defines adequate agitation as that degree of agitation which, at full tank capacity, results in a variation in fat content of the milk in the tank of not more than $\pm 0.1 \% \mathrm{wt} / \mathrm{wt}$ as determined by an official AOAC milkfat test.

Goss (1953) also suggested that the agitation time needed for each type of tank and agitator should be determined empirically for each tank, but this does not seem practical. For example, D. Nolan, Transportation Manager for the Dairy Farmers of Ontario (personal communication, 2001), was able to provide manufacturer and size data for 3812 farm bulk tanks in the province of Ontario, Canada, and size data for an additional 2501 tanks. The data include 25 different manufacturers, many of which are represented by several tank sizes and models. Tank sizes ranged from 600 to $30,000 \mathrm{~L}$. One would suspect that many other variables, such as percent fill, agitator shape and rotation speed, number of agitators, and herd-specific variables, such as fat content, would also play a role in mixing time behavior. Unfortunately, as stated previously, bulk milk-tank manufacturers generally do not provide mixing guidelines.

The only extensive research on bulk-tank mixing that we are aware of is a series of studies described in a technical report by Biggs (1983) and partially published by Biggs et al. (1984). The purpose of the first study by Biggs et al. (1984) was to compare composite to fresh milk-sampling techniques. This study gathered data from 384 milk producers on 9 milk routes over a 2 -yr period. All samples analyzed in the study (fresh and composite) were obtained manually following $5 \mathrm{~min}$ of agitation of the milk in the bulk tank, and used a sanitary straw or a long-handled dipper to obtain a $30-\mathrm{mL}$ sample. The composite samples consisted of seven 30 $\mathrm{mL}$ samples accumulated over a 14-d period in a composite bottle containing potassium dichromate. A 120$\mathrm{mL}$ fresh milk sample was obtained in a similar manner 4 times per month. To test repeatability, duplicate 120 $\mathrm{mL}$ fresh samples were collected once a month from each bulk tank. Additionally, 86 samples were tested in duplicate, and the standard deviation of the differences 
between duplicates was used as an estimate of analytical precision. Fresh and composite samples were analyzed instrumentally using an infrared milk analyzer, which had repeatability error $<0.1 \%$ (Biggs, 1983).

The standard deviation of the test results for duplicate samples after $5 \mathrm{~min}$ of agitation was $\pm 0.215 \%$, wt/ wt. The frequency distribution of the differences between tests on duplicate samples was abnormal; twothirds of the differences were within $\pm 0.13 \%$, wt/wt, a value considerably less than the estimated standard deviation (usually two-thirds of the differences would be distributed within the range of one standard deviation, in this case, $\pm 0.215 \%$, wt/wt). Also, a normal expectation for values outside of 3 standard deviations is 3 in 1000 values. In the population of 307 duplicate tests in this study, the expectation would be one, but 7 values exceeded 3 standard deviations $( \pm 0.64 \%$, wt/wt). Similarly, the standard deviation of the differences between tests on successive pickup days (2956 samples) was estimated at $\pm 0.214 \%$, wt/wt. As with the duplicate samples, the frequency distribution of the differences was abnormal. For this population of 2956 samples, one would expect 9 values to be outside 3 standard deviations, but it was observed that 91 values exceeded $\pm 0.64 \%$, wt/wt. The authors concluded that large differences in fat between duplicate samples and among samples collected on successive days were mainly the result of inadequate mixing in farm bulk tanks.

To prove that $5 \mathrm{~min}$ of agitation was not sufficient to ensure milk homogeneity, the researchers performed a second study (Biggs, 1983). In this experiment, $307 \mathrm{bulk}$ tanks were agitated for $10 \mathrm{~min}$, and 3 samples, one from each end of the tank and one from the middle, were collected. The standard deviation of differences within the 307 groups of 3 samples was $\pm 0.04 \%$, wt/ $\mathrm{wt}$, and the frequency distribution, unlike the 5-min agitation study, was nearly normal. The authors accepted these results as confirmation that the large errors observed in the previous experiment were due to poor mixing, and that agitation for $10 \mathrm{~min}$ was required to ensure homogeneity of the milk. Additional confirmation was obtained in a further study (Biggs, 1983) in which milk was allowed to settle in the tanks for an extended period before sampling. Samples were taken from 3 different locations in several tanks after 5, 10, 15 , and $20 \mathrm{~min}$ of agitation. Tests on triplicate samples agreed within repeatability limits after $10 \mathrm{~min}$ of agitation but did not agree for all tanks after 5 min of agitation.

\section{STRATEGIES TO REDUCE MIXING TIME}

The available reports indicate that, for some quiescent farm tanks, 5 min of agitation is insufficient (Biggs,
1983; Biggs et al., 1984). However, these studies were completed before the widespread use of timed interval agitators. Rather than suggest extended agitation times of up to 10 min, Biggs (1983) recommended the use of interval agitators to agitate the milk automatically for 5 min every hour. This recommendation was accepted and is now prescribed in all Canadian provinces and other jurisdictions in North America, Europe, and elsewhere. It seems obvious that intermittent agitation should reduce the required mixing time, but there does not appear to be any data on which to base revised mixing time recommendations. Nevertheless, the IDF has recommended that mixing times can be reduced to 1 to $2 \mathrm{~min}$ with intermittent agitation (IDF, 1985, 1995).

Intermittent agitation may also help prevent adhesion of fat to the sides of the tank at the surface of the milk, as described by Marshall and Shelley (1981). Marshall and Shelley (1981) also considered the potential impact of churned fat on milkfat analysis and concluded that the effect of churning on milk payment under typical conditions, including intermittent agitation, is probably negligible. However, increased churning due to intermittent agitation could have significant effects on milk quality, such as increased lipolysis. It is also unclear what effects continuous mixing, as required in New Zealand, may have on milk quality.

Intermittent agitation may also be a contributing factor in the occurrence of black specks. In Ontario during 2003 , out of a total of 56 tanker loads that were rejected for various reasons, 17 loads (34\%) were rejected due to black specks (Ontario Dairy Council, 2003). In 2002, 17 out of 59 tanks were rejected due to black specks. Black specks are irregularly shaped particles of about 10 to $20 \mathrm{~mm}$ in diameter (Hill, 1993). They are observed on both farm tanks and bulk milk trucks and appear to be caused by the adsorption of carbon black particles, probably from rubber pump impellers and rubber components of milking systems, to the surface of churned fat droplets. When mechanically disrupted (touched), the black/gray particles immediately disperse throughout the churned fat and become invisible to the naked eye.

Another approach to minimize mixing time before sampling is to use automatic samplers. Biggs (1983) investigated automatic sampling using 4 different systems and found it to be comparable to samples taken manually from the farm bulk tank after the milk had been agitated for $10 \mathrm{~min}$. Bulk tanks were agitated for 10 min during the morning, and then 3 manual samples, one from each end of the tank and one from the middle, were taken. The tank was then left to settle until milk pickup in the afternoon. At that time, a transport truck equipped with an automatic sampler picked 
up the same load of milk that had been manually sampled earlier in the day. The tank was agitated for $30 \mathrm{~s}$ and, as the tank was pumped down, a sample was procured with the automatic sampler installed on the truck. Differences were calculated between the average of the test on the 3 manual samples and the test on the automatic sample. Both frequency distribution and a standard deviation of difference were calculated for the 307 differences obtained from these data. The results showed that, for the 307 differences between averages of 3 manual samples taken after 10 min of mixing and the values for equivalent automatic samples, the estimated standard deviation was $\pm 0.04 \%$, wt/wt. The frequency distribution was abnormal but only slightly so. For this group of differences, the range was small, with no difference exceeding $0.24 \%$, wt/wt. These results provided definite proof that the lack of homogeneity observed between bulk-tank milk samples was the result of poor mixing, and that automatic sampling had the potential to provide excellent representative samples without a lengthy period of premixing.

Other researchers have evaluated different models of autosamplers and in the process demonstrated that the 5-min standard may be inadequate. Marshall and Shelley (1981) collected samples of bulk milk from 102 producers by the conventional procedure of manual sampling. After at least $3 \mathrm{~h}$ of quiescent conditions, samples were collected from the same tanks with the use of an ISOLOK model M-4KSO Mobile Service Sampler (Bristol Engineering, Yorkville, IL), which was mounted on the truck. Milkfat determinations of the samples were calculated. The results showed that there was little variance among the 204 pairs of samples. One pair of samples differed by $0.10 \%$, wt/wt, 15 samples differed by $0.02 \%$, wt/wt, 95 samples differed by $0.01 \%$, $\mathrm{wt} / \mathrm{wt}$, and 93 samples were the same. The overall standard deviation of differences between paired samples in the 204 comparisons was $0.009 \%$, wt/wt. The results also showed that manual sampling produced significantly higher fat tests $(P<0.001)$ than did inline (automatic) sampling. The overall means of milkfat percentage were $3.752 \%$, wt/wt, for samples collected by the inline sampler, and $3.781 \%$, wt/wt, for samples obtained manually, following $5 \mathrm{~min}$ of agitation. If the agitation time was increased from 5 to $8 \mathrm{~min}$, a slight but significant $(P<0.05)$ decrease in average fat content of manual samples was observed. Whereas there was no way to determine whether either sampling method (automatic vs. manual) was used with less error than the other, it was clear that increased agitation time for manual sampling resulted in slightly lower fat estimates, suggesting that $5 \mathrm{~min}$ of agitation was inadequate.

\section{CONCLUSIONS}

There is a consensus in both international standards and the scientific literature that, without intermittent mixing, at least $5 \mathrm{~min}$ of stirring is required to obtain homogeneity in milk-farm bulk tanks. Some jurisdictions, like the Province of Quebec, have circumvented this problem by installing autosamplers on their milk trucks. This will ensure that a representative sample is achieved, but capital investment (Beauséjour, 1992) and maintenance (Johnson, 1978) costs have slowed their adoption in many jurisdictions. New Zealand has decided to ensure homogeneity by constantly stirring all their milk bulk tanks, but the impact of this on milk churning has not been studied in detail.

Some regulatory bodies, such as the IDF, have suggested that the 5-min mixing time standard could be reduced to 1 to $2 \mathrm{~min}$ if intermittent mixing is used (IDF, 1995), and others, like the DFO, have made intermittent mixing mandatory (OMAF, 1983). However, there does not appear to be any consensus regarding the frequency or duration of intermittent agitation required to obtain homogeneity. The combination of a short period of mixing before sampling, combined with intermittent mixing, could potentially provide a costeffective means of ensuring sample homogeneity while maintaining milk quality. Nevertheless, a systematic study is still needed to determine the optimum intermittent agitation protocol and delineate what effect this protocol has on the amount of mixing required to obtain a representative sample from large-scale bulk milk tanks.

\section{ACKNOWLEDGMENTS}

Financial support of the Ontario Ministry of Agriculture and Food and the Dairy Farmers of Ontario is gratefully acknowledged.

\section{REFERENCES}

Anonymous. 1997. Milk Marque Drivers Handbook. Arla Foods, Leeds, UK.

APHA. 1992. Standard Methods for the Examination of Dairy Products. American Public Health Association, Washington, DC.

Beauséjour, M. 1992. Flowmeters and sampling equipment on milk collection tankers: Report of Subject B30. International Dairy Federation Bulletin No. 279, IDF, Brussels, Belgium.

Belknap, R. A., W. L. Arledge, K. W. Whaley, E. O. Wright, and A. F. Zimmerman. 1978. Sampling Dairy and Related Products. Pages 33-40 in Standard Methods for the Examination of Dairy Products. 14th ed. E. H. Marth, ed. American Public Health Association, Washington, DC.

Biggs, D. A. 1983. Fresh Milk Sampling: Technical Report to the Technical Committee of the Ontario Central Milk Testing Laboratory, Guelph, ON.

Biggs, D. A., L. F. Szijarto, and F. R. van de Voort. 1984. Fresh milk sampling for centralized milk testing. J. Dairy Sci. 67:3085-3092.

DFO. 2002. Subject: Dairy Farmers of Ontario 2001 Annual Report. http://www.milk.org/pdf/ar-report.pdf. Accessed Jan. 10, 2003. 
DFSV. 2003. Subject: The code of practice for dairy food safety. Dairy Food Safety Victoria. http://www.dairysafe.vic.gov.au/content/. Accessed July 2003.

DPC. 1991. Subject: Guidelines for the Dairy Industry: DPC 50Farm Bulk Tank Collection Procedures. http://www.dairypc.org/ glabstracts.htm. Accessed July 2003.

Davis, J. G. 1951. Pages 17-23 in Milk Testing: The Laboratory Control of Milk, Dairy Industries Ltd., London, UK.

FPLQ. 1999. Procedure Recommended to the Bulk Milk Grader when Collecting Milk at the Farm. Fédération des Producteurs de Lait du Québec, Longueuil, QC.

Goss, E. F. 1953. Pages 2-9 in Techniques of Dairy Plant Testing. The Iowa State College Press, Ames, IA.

Hill, A. R. 1994. Properties of black specs recovered from bulk milk farm tanks and trucks. Technical Report to the Dairy Farmers of Ontario. Mississauga, ON.

IAFP. 1994. 3-A Sanitary Standards for Farm Milk Cooling and Holding Tanks, Number 13-09 International Association of Food Protection, United States Public Health Service, The Dairy Industry Committee. Dairy Food Environ. Sanitation. 14:106-114.

IDF. 1985. Milk and Milk Products: Guidance on Sampling. International Dairy Federation, Standard 50B, Brussels, Belgium.
IDF. 1995. Milk and Milk Products: Guidance on Sampling. International Dairy Federation, Standard 50C, Brussels, Belgium.

Jackson, A. C. 1981. Agitation and sampling of tankers and storage tanks. J. Soc. Dairy Technol. 34:98-103.

Johnson, R. R. 1978. Online (computerized) milk sampling: Methods and problems. Am. Dairy Rev. 40:34-36.

Marshall, R. T., and D. S. Shelley. 1981. Comparisons of tests of milk samples taken conventionally and with an automatic in-line sampler. J. Food Prot. 44:257-262.

MMP. (Manitoba Milk Producers). 1999. Raw Milk Sampling Procedures, Manitoba Milk Producers, Winnipeg, Manitoba.

OMAF. 1983. The Milk Act and Regulations of Ontario. Ontario Ministry of Agriculture and Food, Toronto, ON.

Ontario Dairy Council. 2003. Raw Milk Quality Statistics and Trends. News and Views. Vol. 5, No. 5.

State of Wisconsin. 1999. Subject: Wisconsin Administrative Code. ATCP 82. http://www.legis.state.wi.us/rsb/code/atcp/atcp.html. Accessed July 2003.

Van Slyke, L. L. 1927. Pages 18-22 in Modern Methods of Testing Milk and Milk Products. Orange Judd 5 Publishing Co., New York, NY. 